\title{
Drug Refraining and Seeking Potentiate Synapses on Distinct Populations of Accumbens Medium Spiny Neurons
}

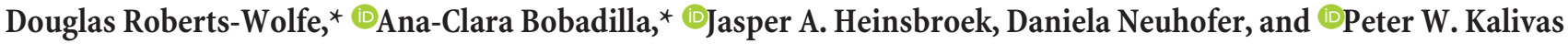 \\ Department of Neuroscience, Medical University of South Carolina, Charleston, South Carolina 29425
}

Cocaine-associated cues and contexts can precipitate drug seeking in humans and in experimental animals. Glutamatergic synapses in the core subcompartment of the nucleus accumbens (NAcore) undergo transient potentiation in response to presenting drug-associated cues. The NAcore contains two populations of medium spiny neurons (MSNs) that differentially express D1 or D2 dopamine receptors. By recording the ratio of AMPA and NMDA glutamate receptor currents (AMPA/NMDA ratio) from MSNs in NAcore tissue slices, we endeavored to understand which subpopulation of MSNs was undergoing transient potentiation. Transgenic female and male mice differentially expressing fluorescent reporters in D1 or D2 MSNs were withdrawn for 2-3 weeks after being trained to self-administer cocaine. In some mice, discrete cocaine-conditioned cues were isolated from the drug-associated context via extinction training, which causes rodents to refrain from drug seeking in the extinguished context. By measuring AMPA/NMDA ratios in the drug context with or without contextual or discrete cues, and with or without extinction training, we made the following three discoveries: (1) mice refraining from cocaine seeking in the extinguished context showed selective elevation in AMPA/NMDA ratios in D2 MSNs; (2) without extinction training, the drug-associated context selectively increased AMPA/NMDA ratios in D1 MSNs; (3) mice undergoing cue-induced cocaine seeking after extinction training in the drug-associated context showed AMPA/NMDA ratio increases in both D1 and D2 MSNs. These findings reveal that the NAcore codes drug seeking through transient potentiation of D1 MSNs, and that refraining from cocaine seeking in an extinguished context is coded through transient potentiation of D2 MSNs.

Key words: AMPA; cocaine; glutamate; reinstatement; self-administration; spiny neurons

Significance Statement

Relapse is a primary symptom of addiction that can involve competition between the desire to use drugs and the desire to refrain from using drugs. Drug-associated cues induce relapse, which is correlated with transiently potentiated glutamatergic synapses in the nucleus accumbens core. We determined which of two cell populations in the accumbens core, D1-expressing or D2-expressing neurons, undergo transient synaptic potentiation. After being trained to self-administer cocaine, mice underwent withdrawal, some with and others without extinguishing responding in the drug-associated context. Extinguished mice showed transient potentiation in D2-expressing neurons in the extinguished environment, and all mice engaged in context-induced or cue-induced drug seeking showed transient potentiation of D1-expressing neurons. A simple binary engram in accumbens for seeking drugs and refraining from drugs offers opportunities for cell-specific therapies.

\section{Introduction}

Relapse is common among those attempting to quit a drug addiction, and the urge to relapse to drug use can be accompanied

Received March 26, 2018; revised June 18, 2018; accepted June 27, 2018.

Author contributions: D.R.-W., A.-C.B., and P.W.K. designed research; D.R.-W., A.-C.B., J.A.H., and D.N. performed research; D.R.-W., A.-C.B., and P.K. analyzed data; D.R.-W. wrote the paper.

This work was supported in part by United States Public Health Service Grants DA038893, GM008716, TR000061, DA012513, DA003906, and DA015369. We thank members of the P.W.K. laboratory for helpful comments on this manuscript; and Eric Dereschewitz, Victoria Chareunsouk, Caleb Shields, and Andrew Motts for technical assistance.

${ }^{*}$ D.R.-W. and A.-C.B. contributed equally to this work.

The authors declare no competing financial interests.

Correspondence should be addressed to either Dr. Douglas Roberts-Wolfe or Dr. Peter W. Kalivas, Medical University of South Carolina, Drug Discovery Building 223, 70 President Street, Charleston, SC 29425, E-mail: roberdj@musc.edu orkalivasp@musc.edu by a countermanding motivation to refrain from drug use (Chen et al., 2013; Tang et al., 2015). Researchers often use reactivity to drug-associated cues to model the neurobiology of the motivation to seek drugs. Through this technique, human imaging and animal studies have found that cue reactivity can be mediated by activating prefrontal cortical glutamatergic projections to the nucleus accumbens (Volkow et al., 2012; Lüscher, 2016; Dong et al., 2017). To isolate and study the neurocircuitry of cue-induced drug seeking, it is common practice to train rodents to refrain from drug seeking in response to being placed in a drug- 
associated context (i.e., extinction training), and re-expose the rodent to discrete drug-associated cues that motivate drug seeking in the absence of drug delivery (Venniro et al., 2016). Using this procedure to initiate drug seeking, the intensity and time course of seeking depend on transient synaptic potentiation $(\mathrm{t}-$ $\mathrm{SP}$ ) at excitatory synapses on medium spiny neurons (MSNs) in the core subcompartment of the nucleus accumbens (NAcore; Gipson et al., 2013a; Smith et al., 2014; Scofield et al., 2016). Only drug-associated cues, and not sucrose-associated cues, induce t-SP (Scofield et al., 2016). t-SP is quantified as transient increases in the ratio of AMPA to NMDA glutamate receptor currents (AMPA/NMDA ratio), in spine head diameter and/or density of MSN dendritic spines, and in the activity of matrix metalloprotease-9 (Gipson et al., 2013a,b; Smith et al., 2014, 2017; Stankeviciute et al., 2014; Spencer et al., 2017). In addition to exploring the neurobiology underpinning cue-induced drug seeking, the extinction training procedure provides an opportunity to understand the neurobiology underpinning how learning to refrain in an extinguished context might countermand cueinduced motivation to seek a drug.

Extinction training-induced refraining from drug seeking relies on learning to uncouple seeking behavior from the drugassociated context over multiple extinction sessions, and enduring neuroadaptations in the nucleus accumbens have been reported after cocaine extinction training (Sutton et al., 2003; Knackstedt et al., 2010). However, researchers do not fully understand the mechanisms that enable extinction learning to compete with cue-induced drug seeking and the associated t-SP. Here we focused on the AMPA/NMDA ratio in tissue slices containing NAcore MSNs as a readout of cue-induced or context-induced $\mathrm{t}$-SP. MSNs constitute $95 \%$ of the neurons in the NAcore and are chemically coded into two numerically equivalent populations that express either D1 or D2 dopamine receptors (Gerfen and Surmeier, 2011). These two populations differentially alter motivated behaviors, such as locomotion and feeding, with activation of D1 MSNs, which promote behavior, and D2 MSNs, which inhibit behavior (Lobo and Nestler, 2011; Kravitz et al., 2012; Bock et al., 2013). Consistent with this characterization and specifically relevant here, cue-induced reinstatement of drug seeking in mice trained to self-administer cocaine is promoted by activating D1 MSNs or inhibiting D2 MSNs (Heinsbroek et al., 2017). The existence of functionally distinct populations of MSNs poses the possibility that refraining from and seeking cocaine may be differentially associated with t-SP in the D2 versus the D1 MSN subpopulations, respectively. We used transgenic mice expressing distinct fluorescent reporters in D1 or D2 MSNs to determine whether extinction training and cue-induced reinstatement produce t-SP in different populations of NAcore MSNs. We found that cued cocaine seeking in mice withdrawn without extinction training produced t-SP only in D1 MSNs, that mice placed in an extinguished context without cues showed t-SP only in D2 MSNs, and that extinguished mice reinstated by cocaine-associated cues in the extinguished context showed t-SP in both D1 and D2 MSNs.

\section{Materials and Methods}

Animals and surgery. All experiments were performed in accordance with the Guide for the Care and Use of Laboratory Animals. Rats used in these experiments were male Sprague Dawley rats (Charles River; weighing 200-225 g upon arrival). Mice were bacterial artificial chromosome (BAC) transgenic heterozygotes (male and female, 20-30 g, Vanderbilt University) expressing either tdTomato under the control of the Drdla promoter (Shuen et al., 2008), eGFP under the control of the Drd2 pro- moter (Gong et al., 2003), or both. Animals were housed in a reverse light cycle vivarium with humidity and temperature controls and were fed $a d$ libitum before the beginning of behavioral experiments, at which point they were mildly food restricted to $\sim 85 \%$ of ad libitum body weight for the duration of the experiments. Animals were anesthetized (mice with isofluorane, induction 3-5\% v/v, maintenance $1-2 \% \mathrm{v} / \mathrm{v}$; rats with ketamine $\mathrm{HCl}$ and xylazine) and implanted with indwelling jugular venous catheters.

Cocaine self-administration. After recovering from surgery, animals began cocaine self-administration in operant chambers equipped with two levers (rats) or two nosepoke (mice) apparatuses, a house light, cue light, and tone generator. The designated active lever or nosepoke delivered an infusion of cocaine (rats: $0.6 \mathrm{mg} / \mathrm{kg} /$ infusion; mice: $1 \mathrm{mg} / \mathrm{kg} /$ infusion) along with a compound cue (light + tone). Following each infusion, a $20 \mathrm{~s}$ time out was signaled by the loss of illumination of the house light, and active lever presses or nosepokes during the timeout were recorded but resulted in no programmed consequence. The designated inactive lever or nosepoke never triggered any programmed consequence. Mice used nosepokes in place of levers throughout selfadministration, extinction, and subsequent testing, as they were unable to maintain stable extinction responding when trained with lever presses.

Extinction/abstinence. Following self-administration, rodents either underwent 2-3 weeks of extinction training or remained abstinent in their home cages. During extinction, active and inactive lever presses or nosepokes were counted but did not result in any programmed consequence. During home-cage abstinence, rodents were handled and weighed daily in the testing room to control for nonspecific components of extinction training.

Tests to assess $t$-SP. Following 2-3 weeks of daily extinction or abstinence, animals destined for baseline measurements of synaptic glutamate transmission were killed without being returned to the operant chamber. Rodents destined for measurements of $\mathrm{t}$-SP were returned to the operant chamber for a test of cocaine seeking. During this test, active lever presses or nosepokes either triggered cues previously present during selfadministration or had no programmed consequence. Rodents were killed after $15 \mathrm{~min}$ (rats) or $30 \mathrm{~min}$ (mice) reinstatement test for preparation of brain slices for electrophysiology. Because rats tend to engage lever-pressing during a reinstatement test more quickly than mice, we allowed $30 \mathrm{~min}$ of reinstatement in mice, rather than the 15 min typically used in rat studies (Gipson et al., 2013a; Smith et al., 2014, 2017).

Electrophysiology: slice preparation. Rodents were anesthetized with ketamine and decapitated $24 \mathrm{~h}$ after the last day of extinction training or withdrawal without extinction training for baseline measurements or after 15 or $30 \mathrm{~min}$ in the operant chamber with or without conditioned cues (see above). The brain was removed and transferred to ice-cold aCSF containing (in $\mathrm{mM}$ ) the following: $126 \mathrm{NaCl}, 2.5 \mathrm{KCl}, 1.2 \mathrm{MgCl}_{2}, 1.4$ $\mathrm{NaH}_{2} \mathrm{PO}_{4}, 2.4 \mathrm{CaCl}_{2}, 11$ glucose, $25 \mathrm{NaHCO}_{3}, 0.4$ ascorbate, 2 pyruvate. Coronal slices $(220 \mu \mathrm{m})$ containing NAcore were prepared on a Leica VT1200S vibratome (Leica). Ice-cold cutting solution contained aCSF and kynurenic acid (5 mM) and D-AP5 $(50 \mu \mathrm{M})$, bubbled continuously with carbogen gas $\left(95 \% \mathrm{O}_{2}, 5 \% \mathrm{CO}_{2}\right)$, and gradually warmed to room temperature $\left(37^{\circ} \mathrm{C}\right)$.

Electrophysiology: recording. Recording "bath" solution contained aCSF and picrotoxin $(0.1 \mathrm{~mm})$ at physiological temperature. Slices were visualized using an Olympus BX51WI fixed stage upright microscope. tdTomato (expressed in D1 MSNs) and eGFP (expressed in D2 MSNs) were visualized using 530 and $460 \mathrm{~nm}$ LEDs (Prizmatix). Recording pipettes (1.9-2.4 M $\Omega$ ) were filled with ice-cold internal solution containing (in mM) the following: 128 CsMs, 1 EGTA, 10 HEPES potassium salt, $1 \mathrm{MgCl}_{2}, 10 \mathrm{NaCl}, 2 \mathrm{Mg}$-ATP, $0.3 \mathrm{Na}-\mathrm{GTP}, 3 \mathrm{QX}-314$-Cl. All recordings were amplified using an Axon/Molecular Devices Multiclamp Amplifier $700 \mathrm{~B}$, digitized at $20 \mathrm{kHz}$, and filtered at $2 \mathrm{kHz}$ using Axograph software.

A bipolar stimulating electrode (FHC) was used to evoke EPSCs between 200 and $450 \mathrm{pA}$. Following $10 \mathrm{~min}$ of cell stabilization at $-80 \mathrm{mV}$ holding potential, EPSCs were evoked in a paired pulse protocol $(50 \mathrm{~ms}$ interstimulus interval), and the paired-pulse ratio (PPR) was calculated by dividing the average amplitude of the second EPSC by the first. Spontaneous EPSCs, detected $\geq 10 \mathrm{~s}$ after the electrical stimulation, were analyzed with regard to their amplitude and frequency. Next, the holding 
A

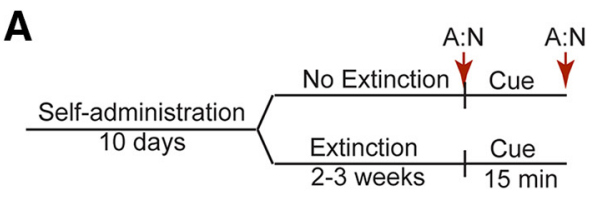

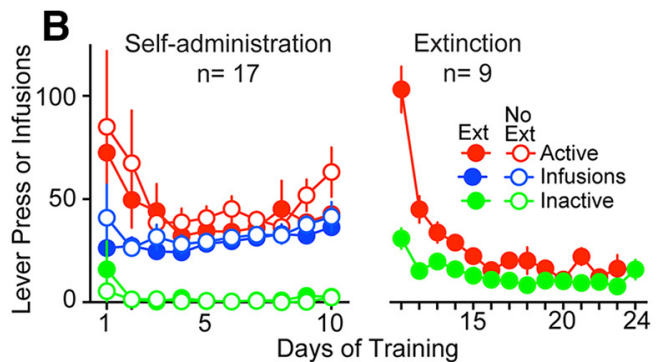

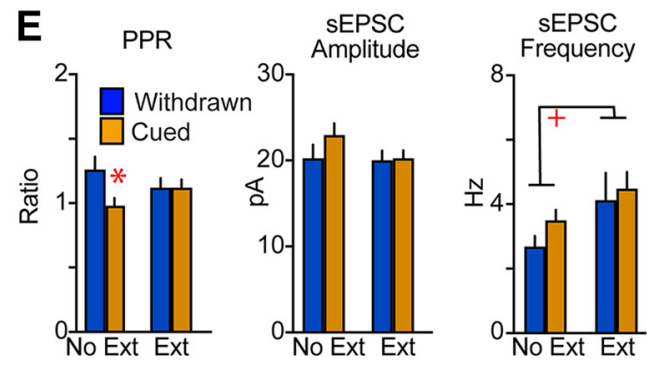

Figure 1. Extinction training reduced cue-induced cocaine seeking and was necessary for cue-induced t-SP. $A$, Treatment protocol for data in Figure 1. Red arrows denote time points for ex vivo measurement of AMPA/NMDA ratio (A:N). Tissue slices were obtained $24 \mathrm{~h}$ after the last day of withdrawal (Withdrawn) or after 15 min of cued reinstatement (Cued). $\boldsymbol{B}$, Cocaine self-administration and extinction training. $\boldsymbol{C}$, Lever presses emitted after 15 min of cue-induced cocaine seeking. $+p<0.05$, comparing active lever presses using a Bonferroni post hoc test. $D$, AMPA/NMDA ratio measured in NAcore MSNs from cocaine-withdrawn rats with or without extinction training and undergoing 15 min of cued cocaine seeking. $E$, Measures of PPR and sEPSC frequency reveal group differences, while no statistical effect was measured for sEPSC amplitude. Data shown as mean \pm SEM. N shown in bars is cells/animals. In representative traces: AMPA, red; NMDA, blue; calibration bar, $20 \mathrm{pA} \times 50 \mathrm{~ms}^{*}{ }^{*} p<0.05$ comparing Withdrawn and Cued groups using a Bonferroni's post hoc test; $+p<0.05$, comparing Extinction and No-extinction groups.

potential was depolarized to $+40 \mathrm{mV}$ and restabilized for an additional 5 min. Dual EPSCs were recorded before application of D-AP5, which isolated the AMPA receptor EPSCs. NMDA receptor EPSCs were calculated by subtracting the average AMPA EPSC from the average dual EPSC, and the AMPA/NMDA ratio was calculated by dividing the peak amplitudes of the AMPA and NMDA EPSCs. Changes in access resistance of $>20 \%$ between the two recording conditions resulted in removal of the cell from further analyses.

Experimental design and statistical analysis. Two-way ANOVAs were conducted to statistically evaluate behavioral and physiological outcomes. Behavioral two-way ANOVAs used a consistent format in which operand (active vs inactive) was a within-subjects factor, and history (extinction vs abstinence) was a between-subjects factor. Two-way ANOVA evaluation of electrophysiological data also used a consistent format for all experiments, in which between-subjects factors were History (i.e., extinction vs abstinence) and Re-exposure (i.e., baseline vs return to operant chamber). A Bonferroni post hoc correction was used to adjust $\alpha$ for multiple comparisons. All data were analyzed using Prism, version 6.0 (GraphPad Software), and outliers were removed using the ROUT module of Prism (Motulsky and Brown, 2006). Across all data, 5 of 181 AMPA/NMDA ratio recordings were deemed outliers. All electrophysiology figures and Bonferroni post hoc tests are calculated using cellbased statistics, but electrophysiology ANOVA $F$ tests are additionally reported in the Results using animal-based statistics (Ma et al., 2014).

\section{Results}

No change in AMPA/NMDA ratios in rats withdrawn without extinction training

We first wanted to determine whether t-SP was induced during cocaine seeking. During $10 \mathrm{~d}$ of cocaine self-administration, rats discriminated between the active and inactive levers [Fig. 1A; two-way ANOVA; main effect $F_{(1,32)}=93.0, p<0.001$; no main effect of time $\left(F_{(7,224)}=1.64 ; p=0.124\right)$ or interaction effect $\left(F_{(7,224)}=1.32 ; p=0.238\right]$. Rats assigned to extinction or abstinence groups self-administered equivalent amounts of cocaine (two-way ANOVA, no effect of group; $F_{(1,15)}=0.857 ; p=0.369$; Fig. $1 B$ ). During extinction training, rats learned to refrain from drug seeking (two-way ANOVA: main effect of time $F_{(5,80)}=$
47.5; $p<0.001$; Bonferroni day 1 vs day $6 p<0.001$ ), and no longer discriminated between the active and inactive levers $\left(F_{(5,80)}=19.0 ; p<0.001\right.$; Bonferroni day 1 active vs inactive $p<$ 0.001 , day $6 p=0.973$; Fig. $1 B$ ). Rats assigned to extinction and abstinence were subdivided into "withdrawn" and "cued" groups. Withdrawn rats were killed without exposure to the drug context, and cued groups were killed 15 min after placing rats into the drug context where cocaine-associated cues were made available on active lever presses. Whole-cell patch recordings of NAcore MSNs were conducted to quantify AMPA/NMDA ratios as a measure of $\mathrm{t}-\mathrm{SP}$.

During 15 min of cued drug seeking, abstinent rats (withdrawn without extinction), compared to extinguished rats, emitted more active lever presses (two-way ANOVA: main effect of active/inactive $F_{(1,10)}=23.32 ; p<0.001$; Bonferroni $p=0.036$; Fig. $1 C$ ), indicating behavioral competition between refraining and drug seeking (Buffalari et al., 2013; Kim et al., 2015; Augur et al., 2016). Surprisingly, we found that extinction was necessary for expressing t-SP during cue-induced cocaine seeking (twoway ANOVA, interaction $F_{(1,45)}=5.68, p=0.022$ by cell; $F_{(1,13)}=6.38, p=0.025$ by animal). No effect of cocaineassociated cues on AMPA/NMDA ratios was seen in the rats without extinction training (Fig. 1D; Bonferroni post hoc $p=0.664$ ). As a positive control, we replicated the previously reported increase in AMPA/NMDA ratios produced in the NAcore of extinguished rats during cue-induced reinstatement (Fig. $1 D$; Bonferroni post hoc $p=0.044$; Gipson et al., 2013a; Smith et al., 2014, 2017; Spencer et al., 2017). Overall, these results indicated that extinction is necessary for expression of the t-SP demonstrated in our previous studies.

A history of extinction training increased sEPSC frequency at baseline (Fig. $1 E ; F_{(1,46)}=5.45, p=0.024$, Bonferroni $p=0.036$ by cell; $F_{(1,12)}=12.32, p=0.004$ by animal), and presentation of a cocaine cue altered PPRs only in rats withdrawn without extinction training (Fig. 1E; interaction $F_{(1,36)}=4.52, p=0.040$; Bon- 
A

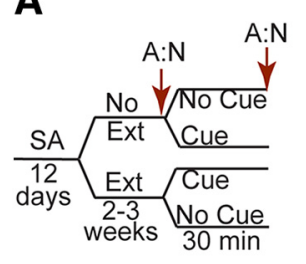

B

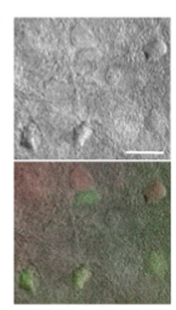

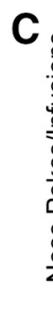

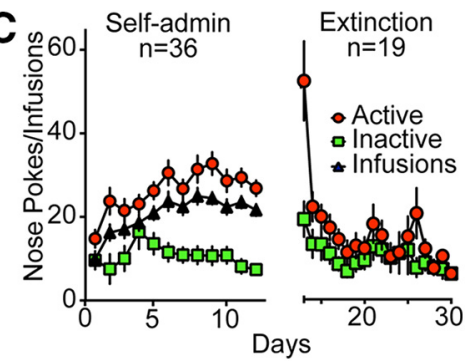

Figure 2. Treatment protocol and behavioral training in D1-MSN and D2-MSN reporter mice. $A$, Treatment protocol for data in Figures 2,3, and 4. Red arrows denote time points for ex vivo measurement of AMPA/NMDA ratio. Tissue slices were obtained $24 \mathrm{~h}$ after the last day of withdrawal with (Ext) or without extinction (№ Ext) training, or after $30 \mathrm{~min}$ in the drug-associated operant context with (Cue) or without conditioned cues (№ Cue). B, Micrographs of brightfield (top) and merge (bottom) showing fluorescent neurons corresponding to D1 and D2 MSNs (tdTomato, red; eGFP, green). Scalebar, $50 \mu \mathrm{m}$. C, Behavioral training in mice undergoing withdrawal with or without extinction training. Data shown as mean $\pm \mathrm{SEM}$.

feronni post hoc $p=0.015$ by cell; $F_{(1,9)}=2.71, p=0.134$ by animal).

\section{Increased AMPA/NMDA ratios in D1 MSNs after cues and in D2 MSNs after withdrawal with extinction training}

The lack of t-SP during cocaine seeking in rats withdrawn without extinction training was surprising given the previously hypothesized causal linkage between NAcore t-SP and cue-induced drug seeking in extinguished rats (Scofield et al., 2016), and that rats extinguished in a nondrug-associated context showed t-SP as measured by increased NAcore MSN spine head diameter in response to a drug-associated context (Stankeviciute et al., 2014). We next explored the possibility that differential expression of AMPA/NMDA ratios in extinguished versus nonextinguished mice might involve distinct D1 versus D2 MSN subpopulations (Fig. 2A). BAC transgenic heterozygous male and female mice expressing either tdTomato under control of the Drdla promoter or eGFP under Drd2 promoter control were crossed to express both reporters in the same NAcore slice (Fig. 2B; Pascoli et al., 2014). Mice were trained to self-administer cocaine over $12 \mathrm{~d}$, then divided into extinction and no-extinction groups (Fig. 2C). During self-administration, mice chose the active significantly more than the inactive operand $\left(F_{(1,62)}=71.3, p<0.001\right.$; Bonferroni active vs inactive $p<0.001$ for days $6-12$ ), and extinction successfully eliminated this goal-directed behavior [interaction of time $\times$ active vs inactive $F_{(9,180)}=7.37, p<0.001$; Bonferroni post hoc first day of extinction active operand was increased relative to other days $(p<0.001)$ but inactive was not $(p>0.10)]$.

On the test day, mice were placed into the drug-associated or extinguished context for $30 \mathrm{~min}$, and NAcore tissue slices were obtained to record AMPA/NMDA ratios (Fig. 2A). Two-way ANOVA of behavior revealed a main effect of active/inactive $\left(F_{(1,22)} 30.45 ; p=0.001\right)$ and extinguished/abstinent $\left(F_{(1,22)}\right.$ $14.75, p=0.001)$. Akin to rats, cue presentation induced higher intensity of cocaine seeking in abstinent compared with extinguished mice (Fig. 3A; Bonferroni post hoc $p=0.001$ ).

Recordings from D1 MSNs revealed that $30 \mathrm{~min}$ of cued cocaine seeking increased AMPA/NMDA ratios in mice regardless of their extinction history (Fig. 3B; two-way ANOVA, main effect of Withdrawn/Cued $F_{(1,41)}=5.36, p=0.026$ by cell; $F_{(1,22)}=4.98, p=0.036$ by animal). In contrast, AMPA/ NMDA ratios in D2 MSNs during cue presentation was higher in extinguished compared with no-extinction mice (Fig. $3 B$; D2 MSNs: two-way ANOVA, interaction $F_{(1,37)}=4.37, p=$ 0.044 , Bonferroni post hoc $p=0.038$ by cell; $F_{(1,21)}=2.53, p=$ 0.127 by animal).

Although the study was relatively under-powered to conduct linear regression analysis, the D1 MSN AMPA/NMDA ratio was found to be highly correlated with cocaine seeking in extinguished mice $\left(r^{2}=0.903, p=0.004, n=6\right)$, which is consistent with previous research on rats where the MSN subtype was not determined (Gipson et al., 2013a; Spencer et al., 2017). No other correlations in this study between AMPA/NMDA ratios and cocaine seeking were statistically significant. Also, no significant differences in PPR, sEPSC amplitude, or sEPSC frequency resulted from extinction or cue-induced cocaine seeking in either D1 or D2 MSNs (Fig. $3 C, D$ ).

\section{AMPA/NMDA ratios increased in D1 MSNs in the cocaine-associated context and in D2 MSNs in the extinguished context}

In the previous experiment, slices were made following cueinduced cocaine seeking in mice withdrawn with or without extinction training. We next determined the role played by context. Extinguished mice and mice withdrawn without extinction training were placed in the drug-associated context without cue presentation for $30 \mathrm{~min}$ (Fig. 2A). Context exposure in no-extinction mice induced substantial drug seeking (two-way ANOVA, Interaction $F_{(1,20)}=5.38, p=0.031$, Bonferroni post hoc $\left.p<0.001\right)$, but less so than context plus cue $\left(F_{(1,22)}=14.8 p<0.001\right.$; compare Figs. $3 A, 4 A)$. The drug-paired and extinction contexts evoked opposite changes in D1 and D2 MSNs (two-way ANOVA, D1 MSNs: Withdrawn/Context $F_{(1,39)}=10.5 ; p=0.003$ by cell; $F_{(1,21)}=10.6 ; p=0.004$ by animal; D2 MSNs: Withdrawn/ Context $F_{(1,40)}=8.05, p=0.007$; No Extinction/Extinction $F_{(1,40)}=5.51, p=0.024$; Interaction $F_{(1,40)}=6.93, p=0.012$ by cell; Interaction $F_{(1,21)}=3.23, p=0.087$ by animal). Recordings made $30 \mathrm{~min}$ after context exposure in no-extinction mice revealed increased AMPA/NMDA ratios in D1 MSNs (Bonferroni post hoc $p=0.020$; Fig. $4 B$ ) but not in D2 MSNs. In contrast, mice refraining from cocaine seeking when returned to the extinguished context displayed the reverse pattern, with D1 MSNs showing no change in AMPA/NMDA ratios and D2 MSNs showing both increased AMPA/NMDA ratios (Fig. 4B; Bonferroni post hoc $p=0.006$ ) and increased sEPSC amplitude (Fig. 4C,D; Withdrawn vs Context, $F_{(1,22)}=8.03, p=0.010$, Bonferroni post hoc $p=0.029$ by cell; $F_{(1,19)}=5.65, p=0.028$ by animal). In addition, D1 MSNs (Fig. $4 C, D ; F_{(1,32)}=5.47, p=0.026$, Bonferroni $p=$ 0.040 by cell; $\left.F_{(1,18)}=6.06, p=0.024\right)$, but not $\mathrm{D} 2 \mathrm{MSNs}$, showed a reduction in sEPSC frequency when animals were re-exposed to the context after extinction versus home-cage abstinence.

\section{Discussion}

The key finding in our study is that t-SP is differentially expressed in NAcore D1 or D2 MSNs depending on whether mice underwent extinction training during cocaine withdrawal to refrain from cocaine seeking in the drug-associated context. D1 MSNs underwent t-SP when cocaine seeking was induced by discrete cocaine-associated light/tone cues, the drug-associated context, or the combination of context and cues. In contrast, D2 MSNs underwent t-SP in response to the extinguished context, regardless of whether cocaine seeking was induced by cocaine- 

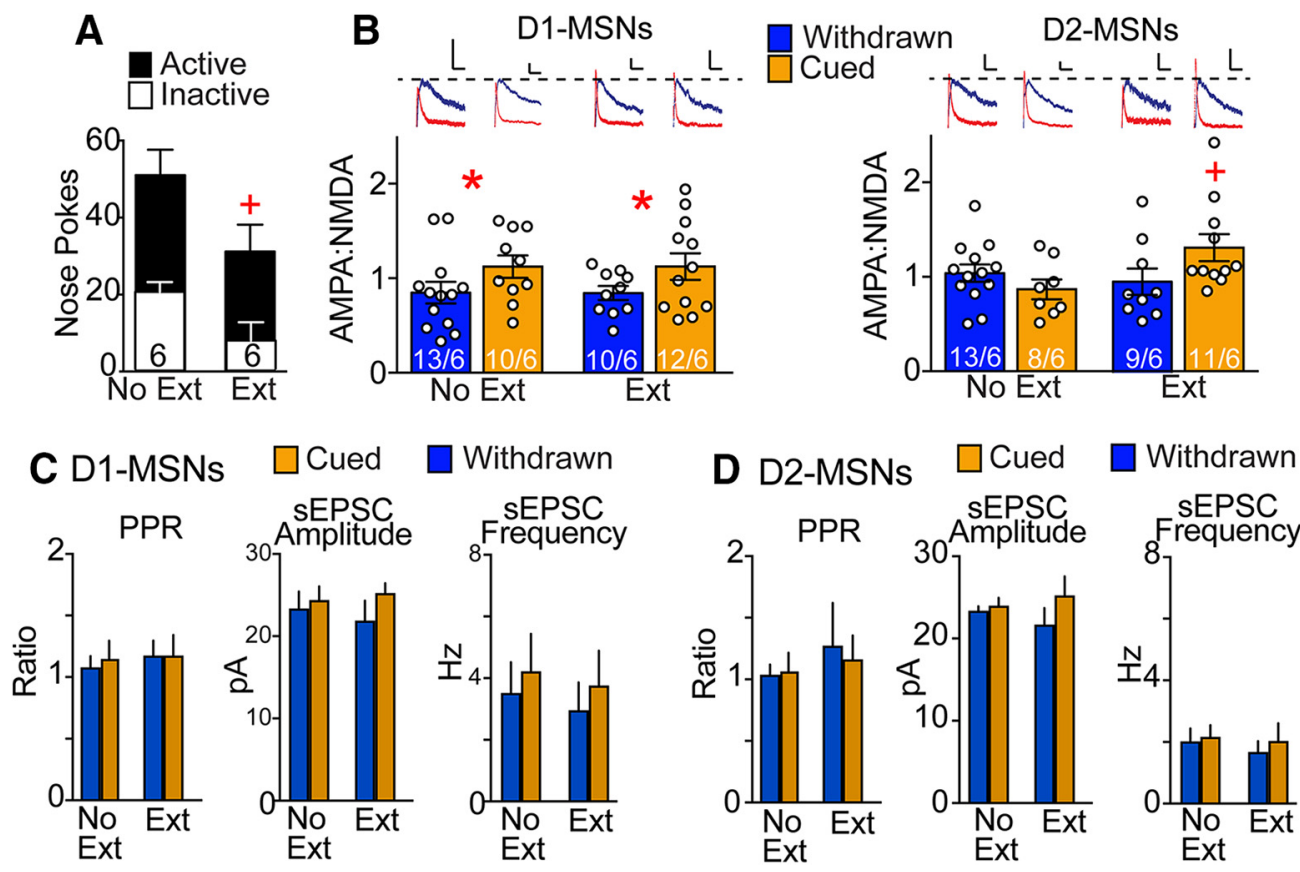

Figure 3. D1-MSN and D2-MSN selective cue-induced increases in AMPA/NMDA ratios depended on withdrawal with (Ext) or without (No Ext) extinction training. $A$, Nose pokes emitted after 30 min of cue-induced cocaine seeking. D1 and D2 transgenic mice were pooled. B, AMPA/NMDA ratios measured in D1 and D2 MSNs from No Ext and Ext groups undergoing cue-induced cocaine seeking. C, Measures from D1 MSNs of PPR and sEPSC frequency and amplitude. No statistically significant comparisons were found. D, Measures from D2 MSNs of PPR and sEPSC frequency and amplitude. No statistically significant comparisons were found. Data shown as mean \pm SEM. N shown in bars indicates cells/animals. In representative traces: AMPA, red; NMDA, blue; calibration bar, $20 \mathrm{pA} \times 50 \mathrm{~ms} .{ }^{*} p<0.05$ comparing Withdrawn and Cued groups. $+p<0.05$, comparing Ext and № Ext groups.
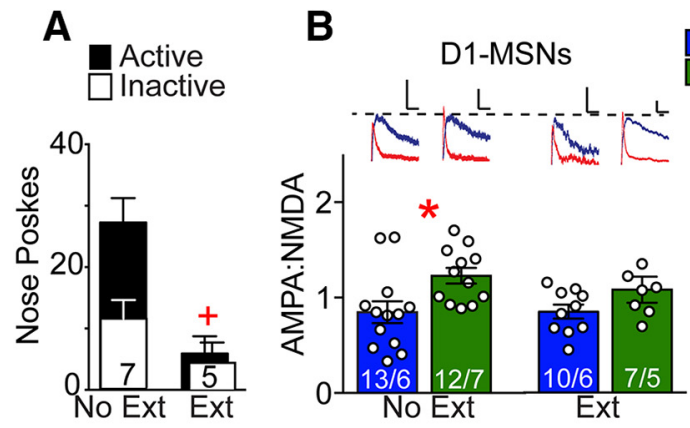

Withdrawn D2-MSNs

Context
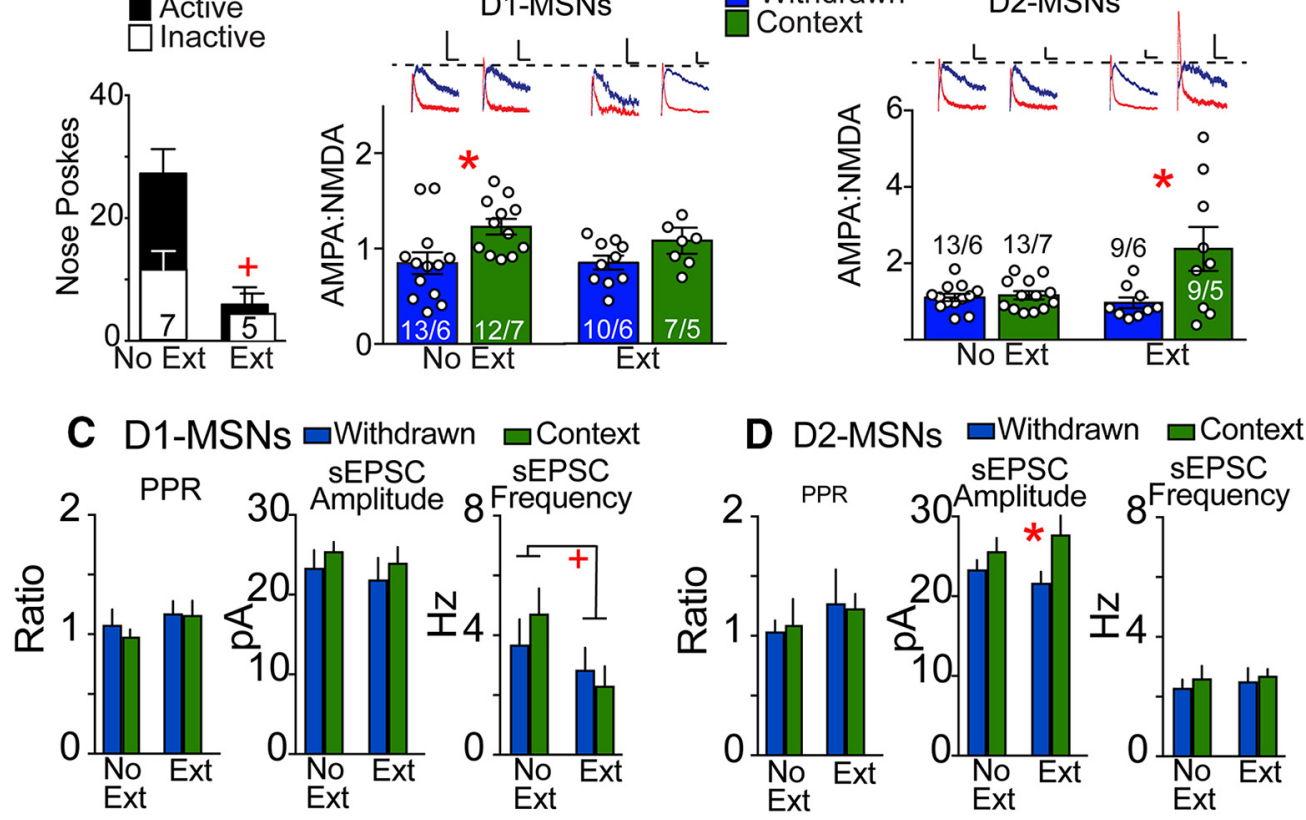

Figure 4. MSN-selective context-induced increases in AMPA/NMDA ratio depended on withdrawal with (Ext) or without (No Ext) extinction training. $A$, Active and inactive nose pokes over 30 min of context-only exposure in No Ext and Ext mice. D1-transgenic and D2-transgenic mice were pooled. $B$, AMPA/NMDA ratio measured in D1 and D2 MSNs from No Ext and Ext mice returned to the drug-associated or extinguished context for $30 \mathrm{~min}$. C, Measures from D1 MSNs of PPR and sEPSC frequency and amplitude obtained from MSNs before quantifying AMPA/NMDA ratio. D, Measures from D2 MSNs of PPR and sEPSC frequency and amplitude obtained from MSNs before quantifying AMPA/NMDA ratio. No statistically significant comparisons were found in PPR or sEPSC frequency. Data shown as mean \pm SEM. N shown in bars indicates cells/animals. In representative traces: AMPA, red; NMDA, blue; calibration bar, $20 \mathrm{pA} \times 50 \mathrm{~ms}$. ${ }^{*} p<0.05$ comparing Withdrawn and Cue or Context groups. $+p<0.05$, comparing active lever or AMPA/NMDA ratios between Extinction (Ext) and No extinction (No Ext) groups.

conditioned cues. Thus, AMPA/NMDA ratios increased in D2 MSNs in the extinguished context when mice were refraining from cocaine seeking and when mice were engaged in cocaine seeking in response to restoring drug-associated cues to the active operand. However, the simultaneous potentiation of D1 and D2 MSNs induced by conditioned cues in the extinguished context reduced the intensity of cocaine seeking elicited by cues in the absence of extinction training. 


\section{Role for t-SP in D1 MSNs in cue-induced and context-induced cocaine seeking}

Our finding that D1 MSN AMPA/NMDA ratios were elevated during reinstated cocaine seeking when induced by discrete drugassociated cues, context, or combined cue + context is consistent with recent reports using a variety of paradigms to show that activation of D1 MSNs, not D2 MSNs, occurs in parallel with engaging a behavior to seek drug reward. For example, cocaine seeking in a conditioned place-preference paradigm is associated with increased calcium fluxes in D1 MSNs as quantified with fiber photometry (Calipari et al., 2016). Also, using the same model of cocaine self-administration and extinction training in transgenic D1-Cre and D2-Cre mice, cue-induced cocaine seeking was augmented by either chemogenic activation of a Gs-coupled designer receptor exclusively activated by a designer drug (DREADD) in D1 MSNs or by inhibiting D2 MSNs via activating a Gi-coupled DREADD in the NAcore (Heinsbroek et al., 2017), and cueinduced reinstatement transiently increases spine head diameter in D1, but not D2, NAcore MSNs (Bobadilla et al., 2017). The functional distinction between the two populations of striatal MSNs in facilitating or inhibiting cocaine seeking is also shown by selectively stimulating D1 or D2 MSNs to facilitate or inhibit, respectively, cocaine-induced motor activity (Ferguson et al., 2011; Bock et al., 2013). Also, stimulating D1 MSNs facilitates reinforcement learning, while stimulating D2 MSNs inhibits reinforcement learning (Kravitz et al., 2012), and depressive behavior is associated with greater activity in D2 MSNs, while resilience to depression is associated with greater D1-MSN activity (Francis et al., 2015). Moreover, optogenetic reversal of D1-MSN synaptic potentiation resulting from exposure to drugs of abuse reverses cocaine-induced or opioid-induced behavioral adaptations, including locomotor sensitization (Creed et al., 2015), conditioned place preference (Hearing et al., 2016), and cocaine-seeking after self-administration (Pascoli et al., 2014). Finally, although chronic opioids produce enduring reductions in excitatory drive and cocaine elicits increases (Robinson and Kolb, 2004; Russo et al., 2010; Scofield et al., 2016), the reduction by opioids is selective for D2 MSNs, while the increase by cocaine occurs on D1 MSNs, and either adaptation is consistent with promoting cueinduced drug seeking (Graziane et al., 2016).

\section{Extinction training induced t-SP selectively in D2 MSNs}

We found that t-SP was induced in D2 MSNs in the NAcore of mice placed in an extinguished context, and that D2 MSNs did not potentiate in animals withdrawn from cocaine without extinction training when placed into the drug-associated context. Moreover, the activation of D2 MSNs in the extinguished environment was associated with reduced cue-induced cocaine seeking compared with mice that did not undergo extinction training. The possibility of a causal relationship between reduced seeking behavior and simultaneous activation of D2 MSNs is directly indicated in the aforementioned study showing that chemogenic inhibition of D2 MSNs or activation of D1 MSNs potentiate cueinduced cocaine reinstatement (Heinsbroek et al., 2017).

The linkage between transient D2-MSN potentiation being induced by an extinguished context and thereby reducing reinstated drug seeking is consistent with previous work suggesting that extinction training reduces drug seeking (Buffalari et al., 2013; Kim et al., 2015; Augur et al., 2016). Interestingly, circuit-level analyses reveal that infralimbic cortex glutamatergic projections to the shell subcompartment of the nucleus accumbens (NAshell) are more critical in the maintenance and expression of extinguished behavior, while projections from the prelimbic cortex to the NAcore regulate rein- stated drug seeking. Thus, pharmacological, DREADD, or optogenetic inhibition of the infralimbic-NAshell projection promotes reinstated or incubated cocaine seeking in an extinguished environment, and activation inhibits cue-induced reinstatement or incubated cocaine seeking (Peters et al., 2008; LaLumiere et al., 2012; Van den Oever et al., 2013; Ma et al., 2014; Augur et al., 2016). Similarly, deep brain stimulation of the NAshell inhibits cocaine-induced reinstatement by antidromic activation of the infralimbic cortex (Vassoler et al., 2013), and reversing the maturation of silent synapses in the NAshell potentiates reinstated cocaine seeking (Ma et al., 2014). These studies together indicate that activation of the infralimbic-toNAshell projection contributes to both the development and expression of extinguished responding in a drug-associated context in rats. Conversely, many studies indicate that the prelimbic projection to NAcore is activated during reinstated cocaine seeking (Stefanik et al., 2013; Shen et al., 2014; McGlinchey et al., 2016), and reversing the maturation of silent synapses in the NAcore inhibits reinstated cocaine seeking (Ma et al., 2014). The infralimbic afferents to the nucleus accumbens are biased toward the NAshell, but also innervate the NAcore (Vertes, 2004). Thus, it is possible that extinctionmediated t-SP in NAcore D2 MSNs might be part of the same extinction circuit involving infralimbic afferents that are distributed more broadly into both the shell and core of the nucleus accumbens. Alternatively, the potentiated D2 MSNs in the NAcore may be regulated by the denser innervation from the prelimbic cortex, which has been proven to have an important role in promoting cocaine seeking. In this scenario, the two subpopulations of MSNs would directly compete in regulating cocaine seeking, with the D1 MSNs being potentiated in response to a cue or context signaling drug availability, and the D2 MSNs potentiating in response to an extinguished drug-associated environment. This possibility is indicated by the behavioral competition we observed between refraining in the extinguished context and cue-induced cocaine seeking. Thus, the capacity of cues to reinstate cocaine seeking was blunted in an extinguished context compared with cue-induced cocaine seeking in a cocaine-associated context without intervening extinction training. The locus of competition between the two MSN populations could be at the level of NAcore local circuitry where GABAergic lateral inhibition of D2 MSNs onto D1 MSNs decreases behavioral responding (Burke et al., 2017). Alternatively, competition may occur at the level of D1-MSN and D2-MSN projections to the ventral pallidum (Kupchik et al., 2015), which undergoes substantial plasticity in response to cocaine self-administration (Kupchik et al., 2014; Heinsbroek et al., 2017), and appears to mediate both the reinforcing and anhedonic properties of cocaine that depend on D1-MSN and D2-MSN afferents, respectively (Creed et al., 2016).

\section{Inconsistencies between sEPSCs and AMPA/NMDA ratios}

We generally found here and in a previous study (Smith et al., 2014) that transient cocaine seeking-associated increases in AMPA/NMDA ratios were not paralleled by increases in sEPSC amplitude, which is also a measure of postsynaptic sensitivity. These paradoxical results are most readily explained by postulating that an increased AMPA/NMDA ratio occurs as a subset of excitatory afferents, while sEPSCs arise from a more diverse population of inputs, many of which are not potentiated. This interpretation is supported by showing that, although repeated cocaine decreases AMPA/NMDA ratios in NAshell neurons without a corresponding decrease in mEPSC amplitude, evoked EPSCs recorded in the presence of strontium display reduced amplitude (Thomas et al., 2001). In this context, it is interesting that during refraining in the extinguished context, D2 MSNs displayed increases in both AMPA/NMDA ratios and sEPSC ampli- 
tude (Fig. 4D). This suggests that the potentiation of D2 MSNs in an extinguished context may involve distinct excitatory afferents from those inputting D1 MSNs during cue-induced or contextinduced cocaine seeking and t-SP (see above). However, the question of which afferents regulate $\mathrm{t}-\mathrm{SP}$ requires direct optogenetic evaluation not only of distinct cortical inputs, but also of allocortical and thalamic excitatory inputs to D1 and D2 MSNs (Britt et al., 2012). Analysis of sEPSCs also revealed presynaptic suppression of D1-MSN inputs during exposure to the extinguished context compared with the drug-associated context (Fig. 4C). A similar observation was made in MSNs from rats in extinction from conditioned-place preference (Lee et al., 2016), and suggests the possibility of a second extinction-associated adaptation that leads to selective presynaptic inhibition of D1 MSNs upon context re-exposure.

\section{Conclusions}

We find a functional and physiological dichotomy between D1 and D2 MSNs in the NAcore in promoting cocaine seeking and refraining from cocaine seeking, respectively. Thus, D1 MSNs show an increase in AMPA/NMDA ratio during cocaine seeking regardless of whether seeking was triggered by drug-associated context, cue, or a combination of both. Conversely, the D2-MSN AMPA/NMDA ratio was elevated in an extinguished context regardless of whether mice were reinstated by the light/toneconditioned cues. Together, our data reveal a nuanced regulation of different populations of accumbens MSNs depending on the withdrawal paradigm and the means of inducing cocaine seeking. Further analysis of more discrete subpopulations of MSNs is warranted to understand how relapse is regulated through t-SP in the NAcore.

\section{References}

Augur IF, Wyckoff AR, Aston-Jones G, Kalivas PW, Peters J (2016) Chemogenetic activation of an extinction neural circuit reduces cue-induced reinstatement of cocaine seeking. J Neurosci 36:10174-10180. CrossRef Medline

Bobadilla AC, Heinsbroek JA, Gipson CD, Griffin WC, Fowler CD, Kenny PJ, Kalivas PW (2017) Corticostriatal plasticity, neuronal ensembles and regulation of drug-seeking behavior. Prog Brain Res 235:93-112. CrossRef Medline

Bock R, Shin JH, Kaplan AR, Dobi A, Markey E, Kramer PF, Gremel CM, Christensen CH, Adrover MF, Alvarez VA (2013) Strengthening the accumbal indirect pathway promotes resilience to compulsive cocaine use. Nat Neurosci 16:632-638. CrossRef Medline

Britt JP, Benaliouad F, McDevitt RA, Stuber GD, Wise RA, Bonci A (2012) Synaptic and behavioral profile of multiple glutamatergic inputs to the nucleus accumbens. Neuron 76:790 - 803. CrossRef Medline

Buffalari DM, Feltenstein MW, See RE (2013) The effects of varied extinction procedures on contingent cue-induced reinstatement in SpragueDawley rats. Psychopharmacology (Berl) 230:319-327. CrossRef Medline

Burke DA, Rotstein HG, Alvarez VA (2017) Striatal local circuitry: a new framework for lateral inhibition. Neuron 96:267-284. CrossRef Medline

Calipari ES, Bagot RC, Purushothaman I, Davidson TJ, Yorgason JT, Peña CJ, Walker DM, Pirpinias ST, Guise KG, Ramakrishnan C, Deisseroth K, Nestler EJ (2016) In vivo imaging identifies temporal signature of D1 and D2 medium spiny neurons in cocaine reward. Proc Natl Acad Sci U S A 113:2726-2731. CrossRef Medline

Chen BT, Yau HJ, Hatch C, Kusumoto-Yoshida I, Cho SL, Hopf FW, Bonci A (2013) Rescuing cocaine-induced prefrontal cortex hypoactivity prevents compulsive cocaine seeking. Nature 496:359-362. CrossRef Medline

Creed M, Pascoli VJ, Lüscher C (2015) Addiction therapy. refining deep brain stimulation to emulate optogenetic treatment of synaptic pathology. Science 347:659-664. CrossRef Medline

Creed M, Ntamati NR, Chandra R, Lobo MK, Lüscher C (2016) Convergence of reinforcing and anhedonic cocaine effects in the ventral pallidum. Neuron 92:214-226. CrossRef Medline
Dong Y, Taylor JR, Wolf ME, Shaham Y (2017) Circuit and synaptic plasticity mechanisms of drug relapse. J Neurosci 37:10867-10876. CrossRef Medline

Ferguson SM, Eskenazi D, Ishikawa M, Wanat MJ, Phillips PE, Dong Y, Roth BL, Neumaier JF (2011) Transient neuronal inhibition reveals opposing roles of indirect and direct pathways in sensitization. Nat Neurosci 14:2224. CrossRef Medline

Francis TC, Chandra R, Friend DM, Finkel E, Dayrit G, Miranda J, Brooks JM, Iñiguez SD, O’Donnell P, Kravitz A, Lobo MK (2015) Nucleus accumbens medium spiny neuron subtypes mediate depression-related outcomes to social defeat stress. Biol Psychiatry 77:212-222. CrossRef Medline

Gerfen CR, Surmeier DJ (2011) Modulation of striatal projection systems by dopamine. Annu Rev Neurosci 34:441-466. CrossRef Medline

Gipson CD, Kupchik YM, Shen H, Reissner KJ, Thomas CA, Kalivas PW (2013a) Relapse induced by cues predicting cocaine depends on rapid, transient synaptic potentiation. Neuron 77:867-872. CrossRef Medline

Gipson CD, Reissner KJ, Kupchik YM, Smith AC, Stankeviciute N, HensleySimon ME, Kalivas PW (2013b) Reinstatement of nicotine seeking is mediated by glutamatergic plasticity. Proc Natl Acad Sci U S A 110:91249129. CrossRef Medline

Gong S, Zheng C, Doughty ML, Losos K, Didkovsky N, Schambra UB, Nowak NJ, Joyner A, Leblanc G, Hatten ME, Heintz N (2003) A gene expression atlas of the central nervous system based on bacterial artificial chromosomes. Nature 425:917-925. CrossRef Medline

Graziane NM, Sun S, Wright WJ, Jang D, Liu Z, Huang YH, Nestler EJ, Wang YT, Schlüter OM, Dong Y (2016) Opposing mechanisms mediate morphine- and cocaine-induced generation of silent synapses. Nat Neurosci 19:915-925. CrossRef Medline

Hearing MC, Jedynak J, Ebner SR, Ingebretson A, Asp AJ, Fischer RA, Schmidt C, Larson EB, Thomas MJ (2016) Reversal of morphineinduced cell-type-specific synaptic plasticity in the nucleus accumbens shell blocks reinstatement. Proc Natl Acad Sci U S A 113:757-762. CrossRef Medline

Heinsbroek JA, Neuhofer DN, Griffin WC 3rd, Siegel GS, Bobadilla AC, Kupchik YM, Kalivas PW (2017) Loss of plasticity in the D2-accumbens pallidal pathway promotes cocaine seeking. J Neurosci 37:757-767. CrossRef Medline

Kim JH, Perry C, Luikinga S, Zbukvic I, Brown RM, Lawrence AJ (2015) Extinction of a cocaine-taking context that protects against drug-primed reinstatement is dependent on the metabotropic glutamate 5 receptor. Addict Biol 20:482-489. CrossRef Medline

Knackstedt LA, Moussawi K, Lalumiere R, Schwendt M, Klugmann M, Kalivas PW (2010) Extinction training after cocaine self-administration induces glutamatergic plasticity to inhibit cocaine seeking. J Neurosci 30 : 7984-7992. CrossRef Medline

Kravitz AV, Tye LD, Kreitzer AC (2012) Distinct roles for direct and indirect pathway striatal neurons in reinforcement. Nat Neurosci 15:816-818. CrossRef Medline

Kupchik YM, Scofield MD, Rice KC, Cheng K, Roques BP, Kalivas PW (2014) Cocaine dysregulates opioid gating of GABA neurotransmission in the ventral pallidum. J Neurosci 34:1057-1066. CrossRef Medline

Kupchik YM, Brown RM, Heinsbroek JA, Lobo MK, Schwartz DJ, Kalivas PW (2015) Coding the direct/indirect pathways by D1 and D2 receptors is not valid for accumbens projections. Nat Neurosci 18:1230-1232. CrossRef Medline

LaLumiere RT, Smith KC, Kalivas PW (2012) Neural circuit competition in cocaine-seeking: roles of the infralimbic cortex and nucleus accumbens shell. Eur J Neurosci 35:614-622. CrossRef Medline

Lee J, Finkelstein J, Choi JY, Witten IB (2016) Linking cholinergic interneurons, synaptic plasticity, and behavior during the extinction of a cocainecontext association. Neuron 90:1071-1085. CrossRef Medline

Lobo MK, Nestler EJ (2011) The striatal balancing act in drug addiction: distinct roles of direct and indirect pathway medium spiny neurons. Front Neuroanat 5:41. Medline

Lüscher C (2016) The emergence of a circuit model for addiction. Annu Rev Neurosci 39:257-276. CrossRef Medline

Ma YY, Lee BR, Wang X, Guo C, Liu L, Cui R, Lan Y, Balcita-Pedicino JJ, Wolf ME, Sesack SR, Shaham Y, Schlüter OM, Huang YH, Dong Y (2014) Bidirectional modulation of incubation of cocaine craving by silent synapse-based remodeling of prefrontal cortex to accumbens projections. Neuron 83:1453-1467. CrossRef Medline 
McGlinchey EM, James MH, Mahler SV, Pantazis C, Aston-Jones G (2016) Prelimbic to accumbens core pathway is recruited in a dopaminedependent manner to drive cued reinstatement of cocaine seeking. J Neurosci 36:8700-8711. CrossRef Medline

Motulsky HJ, Brown RE (2006) Detecting outliers when fitting data with nonlinear regression - a new method based on robust nonlinear regression and the false discovery rate. BMC Bioinformatics 7:123. CrossRef Medline

Pascoli V, Terrier J, Espallergues J, Valjent E, O’Connor EC, Lüscher C (2014) Contrasting forms of cocaine-evoked plasticity control components of relapse. Nature 509:459-464. CrossRef Medline

Peters J, LaLumiere RT, Kalivas PW (2008) Infralimbic prefrontal cortex is responsible for inhibiting cocaine seeking in extinguished rats. J Neurosci 28:6046-6053. CrossRef Medline

Robinson TE, Kolb B (2004) Structural plasticity associated with exposure to drugs of abuse. Neuropharmacology 47 [Suppl. 1]:33-46. CrossRef Medline

Russo SJ, Dietz DM, Dumitriu D, Morrison JH, Malenka RC, Nestler EJ (2010) The addicted synapse: mechanisms of synaptic and structural plasticity in nucleus accumbens. Trends Neurosci 33:267-276. CrossRef Medline

Scofield MD, Heinsbroek JA, Gipson CD, Kupchik YM, Spencer S, Smith AC, Roberts-Wolfe D, Kalivas PW (2016) The nucleus accumbens: mechanisms of addiction across drug classes reflect the importance of glutamate homeostasis. Pharmacol Rev 68:816-871. CrossRef Medline

Shen HW, Gipson CD, Huits M, Kalivas PW (2014) Prelimbic cortex and ventral tegmental area modulate synaptic plasticity differentially in nucleus accumbens during cocaine-reinstated drug seeking. Neuropsychopharmacology 39:1169-1177. CrossRef Medline

Shuen JA, Chen M, Gloss B, Calakos N (2008) Drd1a-tdTomato BAC transgenic mice for simultaneous visualization of medium spiny neurons in the direct and indirect pathways of the basal ganglia. J Neurosci 28:26812685. CrossRef Medline

Smith AC, Kupchik YM, Scofield MD, Gipson CD, Wiggins A, Thomas CA, Kalivas PW (2014) Synaptic plasticity mediating cocaine relapse requires matrix metalloproteinases. Nat Neurosci 17:1655-1657. CrossRef Medline

Smith ACW, Scofield MD, Heinsbroek JA, Gipson CD, Neuhofer D, RobertsWolfe DJ, Spencer S, Garcia-Keller C, Stankeviciute NM, Smith RJ, Allen NP, Lorang MR, Griffin WC 3rd, Boger HA, Kalivas PW (2017) Accum- bens nNOS interneurons regulate cocaine relapse. J Neurosci 37:742-756. CrossRef Medline

Spencer S, Garcia-Keller C, Roberts-Wolfe D, Heinsbroek JA, Mulvaney M, Sorrell A, Kalivas PW (2017) Cocaine use reverses striatal plasticity produced during cocaine seeking. Biol Psychiatry 81:616-624. CrossRef Medline

Stankeviciute NM, Scofield MD, Kalivas PW, Gipson CD (2014) Rapid, transient potentiation of dendritic spines in context-induced relapse to cocaine seeking. Addict Biol 19:972-974. CrossRef Medline

Stefanik MT, Moussawi K, Kupchik YM, Smith KC, Miller RL, Huff ML, Deisseroth K, Kalivas PW, LaLumiere RT (2013) Optogenetic inhibition of cocaine seeking in rats. Addict Biol 18:50-53. CrossRef Medline

Sutton MA, Schmidt EF, Choi KH, Schad CA, Whisler K, Simmons D, Karanian DA, Monteggia LM, Neve RL, Self DW (2003) Extinction-induced upregulation in AMPA receptors reduces cocaine-seeking behaviour. Nature 421:70-75. CrossRef Medline

Tang YY, Posner MI, Rothbart MK, Volkow ND (2015) Circuitry of selfcontrol and its role in reducing addiction. Trends Cogn Sci 19:439-444. CrossRef Medline

Thomas MJ, Beurrier C, Bonci A, Malenka RC (2001) Long-term depression in the nucleus accumbens: a neural correlate of behavioral sensitization to cocaine. Nat Neurosci 4:1217-1223. CrossRef Medline

Van den Oever MC, Rotaru DC, Heinsbroek JA, Gouwenberg Y, Deisseroth K, Stuber GD, Mansvelder HD, Smit AB (2013) Ventromedial prefrontal cortex pyramidal cells have a temporal dynamic role in recall and extinction of cocaine-associated memory. J Neurosci 33:18225-18233. CrossRef Medline

Vassoler FM, White SL, Hopkins TJ, Guercio LA, Espallergues J, Berton O, Schmidt HD, Pierce RC (2013) Deep brain stimulation of the nucleus accumbens shell attenuates cocaine reinstatement through local and antidromic activation. J Neurosci 33:14446-14454. CrossRef Medline

Venniro M, Caprioli D, Shaham Y (2016) Animal models of drug relapse and craving: from drug priming-induced reinstatement to incubation of craving after voluntary abstinence. Prog Brain Res 224:25-52. CrossRef Medline

Vertes RP (2004) Differential projections of the infralimbic and prelimbic cortex in the rat. Synapse 51:32-58. CrossRef Medline

Volkow ND, Wang GJ, Fowler JS, Tomasi D (2012) Addiction circuitry in the human brain. Annu Rev Pharmacol Toxicol 52:321-336. CrossRef Medline 